\title{
BACKGROUND SUBTRACTION BERBASIS SELF ORGANIZING MAP UNTUK DETEKSI OBJEK BERGERAK
}

\author{
Noor Wahyudi ${ }^{1)}$, Vincent Suhartono ${ }^{2)}$, Ricardus Anggi Pramunendar ${ }^{3)}$ \\ ${ }^{1)}$ Fakultas Sains dan Teknologi Universitas Islam Negeri Sunan Ampel Surabaya 1) \\ ${ }^{2), 3)}$ Fakultas Ilmu Komputer, Universitas Dian Nuswantoro, Semarang \\ e-mail: n.wahyudi@uinsby.ac.id1),ricardus.anggi@dsn.dinus.ac.id 2) \\ vincent.suhartono@dsn.dinus.ac.id3)
}

\begin{abstract}
Abstrak
First part in automatic video analisys is moving object detection. An accurate moving object detection is needed indeed to next step process of automatic video analisys like tracking object detected adn then analyze of detected object. Background Subtraction is a common approach in moving object detection. The common problems in background subtraction are illumination changes, object shadow, and dynamic background like waving tree. Self organizing Maps algorithm apllied in background Subtraction to handles these common problems. Median filtering and morphological operation added after background Subtraction procces in conjunction to increase and produce accurate moving object detection. Apllied SOM, median filtering, and morphological operation in background subtraction increasing object detection accuraccy with value of MSE in 1463,73 and PSNR in 17,035 compare with alpha based background Subtraction where 4268,50 for MSE and 12,018 for PSNR.
\end{abstract}

Kata Kunci: Background Substrction, Self Organizing Map, Morfologi, Median filter

\section{PENDAHULUAN}

Video surveillance adalah proses analisis dari sekuen video yang merupakan tema yang aktif dalam Computer Vision. Video surveillance terbagi dalam 3 langkah utama: pertama yaitu deteksi objek, tracking(pelacakan) objek dari frame ke frame, dan analisis dari objek yang terlacak[1]. Deteksi objek dilakukan pada setiap frame atau saat objek pertama kali muncul. Sebagai langkah pertama dari video surveillance, deteksi objek yang akurat menjadi hal yang penting. Hal tersebut tidak mudah tentunya, dengan beberapa permasalahan umum dalam deteksi objek seperti perubahan pencahayaan, dan juga bayangan dari objek yang terdeteksi[2-4].

Pendekatan umum dari untuk deteksi objek adalah menggunakan informasi dari setiap frame. Namun, beberapa metode deteksi objek menggunakan informasi temporal yang didapat dari perhitungan urutan frame dengan tujuan mengurangi kesalahan deteksi(deteksi palsu). Informasi temporal biasanya diperoleh dari perbedaan frame, dimana memilih dan menandai area yang berubah secara dinamis. Kemudian proses tracking dijalankan untuk melacak korespondensi objek dari satu frame ke frame berikutnya yang menghasilkan jalur.
Tujuan utama dari deteksi objek adalah untuk membedakan objek foreground dan background. Langkah awal deteksi objek bergerak adalah inisialisasi background scene Langkah selanjutnya pada deteksi adalah mendeteksi pixel foreground dengan mencari selisih dari model background dan frame saat ini. Level pixel terdeteksi tergantung dari model background dan digunakan untuk meng-update model background untuk beradaptasi dengan perubahan scene yang dinamis.

Hasil output dari deteksi foreground masih mengandung noise. Beberapa faktor yang menyebabkan noise pada deteksi foregorund seperti: noise camera, backgroundcoloredobjectnoise, reflectance noise[6]. Noise dapat direduksi dengan teknik filtering. Lowpassfilter dan operasi morfologi dapat diaplikasikan pada pixel map untuk menghilangkan noise yang disebabkan oleh permasalahan diatas[4]. Tujuan dari menggunakan operasi ini adalah untuk menghilangkan noise yang tidak berhubungan dengan daerah foreground, noise pixel background disekitar dan didalam daerah objek yang termasuk sebagai pixel foreground. Low pass filter digunakan untuk mengaburkan dan mengurangi noise. 
Sesudah noise pixel-level dihilangkan, masih ada beberapa region kecil dikarenakan segmentasi yang buruk. Untuk menghilangkan tipe region ini, digunakan nilai threshold yang akan menghilangkan region yang nilainya lebih kecil dari threshold. Kemudian region atau objek yang tersegmentasi dapat diekstrak dari citra. Fitur dapat berupa ukuran, titik pusat dan bounded dari connected component. Fitur-fitur tersebut dapat digunakan untuk pelacakan objek dan klasifikasi untuk proses selanjutnya setelah proses deteksi.

Yilmaz[1] merangkumkan teknik deteksi objek dalam beberapa kategori: Point Detector, Segmentation, Background Modelling, dan Supervised Classifer. Background Modelling atau Background Subtraction merupakan salah satu teknik deteksi objek yang menarik banyak peneliti. Deteksi objek diperoleh dengan membangun sebuah representasi dari scene yang disebut model latar belakang dan kemudian menemukan perbedaan dari model dan frame yang masuk. Setiap perubahan yang signifikan dalam wilayah gambar dari model latar belakang menandakan objek bergerak. Pixel daerah yang mengalami perbedaan akan ditandai untuk pemrosesan lebih lanjut proses ini disebut background subtraction(BS).

Diungkapkan ada beberapa kendala dalam penggunaan teknik background subtraction seperti: kualitas citra yang buruk, peralihan pencahayaan, bayangan dari objek. Kendala tersebut menjadi tantangan bagi para peneliti dalam mengajukan teknik deteksi dan pelacakan objek yang berbasis teknik pengurangan background. Beberapa teknik BSdiuraikan dalam [4], seperti penelitian oleh Li[7] mengusulkan metode berbasis Bayes untuk deteksi dan segmentasi foreground dari background statis dan bergerak. Zivkovic[8] mengusulkan metode baru dari GaussianMixtureModel(GMM) yang dapat mengurangi waktu pemrosesan meningkatkan akurasi baik dalam background statis maupun bergerak. Kim[9] mengajukan sebuah algoritma Codebooks yang digunakan kompresi background untuk mempelajari variasi sturktur background dalam jangka waktu yang panjang dan jumlah memory terbatas.

Arief[10] menggunakan algoritma Fuzzy CMeans dalam menentukan threshold adaptif untuk segmentasi. Nilai threshold dari Fuzzy C-Means menghasilkan nilai akurasi yang lebih baik pada segmentasi objek bergerak dibandingkan dengan nilai threshold dari Otsu.

Maddalena[11] mengajukan teknik $B S$ yang dikombinasikan dengan algoritma neural network yaitu SelfOrganizingMap. Algoritma SOM yang diterapkan memisahkan pixel background dan foreground pada citra. Beberapa permasalahan umum dari backgroundsubtraction [2] juga dapat diatasi. Hasil deteksi dengan nilai Pada penelitian selanjutnya [12] menerapkan $B S$ berbasis SOM[11] untuk deteksi objek pada kamera stationer.

SelfOrganizingMaps merupakan salah satu algoritma dalam ArtificialNeuralNetwork(ANN) yang termasuk jenis pola pembelajaran tanpa supervisi(unsupervised). SOM bekerja dengan prinsip WinnertakesAll(WTA) dimana dari beberapa node keluaran yang berkompetisi hanya ada satu pemenang dan peng-updetan bobot hanya dilakukan pada node pemenang[13]. Salah satu kelebihan dari SOM yaitu dapat memproses data berdimensi tinggi dan mengurangi dimensi data. Dalam beberapa penelitian, SOM diaplikasikan pada bidang data mining untuk ekstraksi fitur[14], atau sebagai teknik clustering. Dalam bidang pengolahan citra dan komputer visi, SOM diaplikasikan pada pelacakan objek[15], dan pada [16] diaplikasikan sebagai threshold adaptif untuk segmentasi citra.

Dalam rangka menghasilkan deteksi objek yang akurat, penelitian ini menerapkan SOM pada teknik background subtraction. SOM akan mengelompokkan pixel dalam 2 kluster yaitu background dan foreground berdasarkan perbedaan nilai warna pixel dari setiap frame. Pada evaluasi teknik $B S[3]$ disebutkan bahwa $B S$ mempunyai permasalahan pada pencahayaan. Permasalahan ini dapat direduksi atau dihilangkan dengan mengaplikasikan teknik peningkatan kualitas citra yang akan memperbaiki kualitas citra hasil segmentasi dan membantu meningkatkan akurasi deteksi objek bergerak. Teknik peningkatan kualitas citra yang diaplikasikan yaitu: OperasiMorfologi dan Medianfiltering.

\section{PENELITIAN TERKAIT}

Dalam penelitian yang dilakukan oleh Brutzer[3] mengevaluasi metode background subtraction $(B S)$ yang telah diajukan oleh beberapa peneliti Kim[9], Zivkovic[8], Maddalena[11], Li[7]. Beberapa metode tersebut dievaluasi dalam mengatasi permasalahan umum dari teknik BSseperti: kualitas citra yang buruk, peralihan pencahayaan, bayangan dari objek, kamuflase dan background dinamis[2]. Penambahan tahap pemrosesan akhir setelah $B S$ dapat meningkatkan akurasi deteksi objek. Tahap pemrosesan akhir ini diisi dengan teknik filtering.Fase $B S$ dimulai dengan membaca frame video, dari frame video 


\section{SYSTEMIC}

Vol. 1, No. 1, Agustus 2015, 42-51

diinisialisasi model background. Kemudian frame video masukan selanjutnya dibandingkan dengan model background. Selisih nilai pixel merupakan foreground yang terdeteksi. Selanjutnya foreground terdeteksi masuk dalam tahap pemrosesan akhir untuk memperbaiki kualitas foreground yang meningkatkan kualitas deteksi objek.

Penelitian yang dilakukan oleh Maddalena[11] sebuah pendekatan berbasis SelfOrganizingMap(SOM) untuk mendeteksi foreground dari teknik (BS). SOM yang diaplikasikan dapat mengatasi permasalahan umum dari teknik $B S[2]$ seperti: background yang bergerak, dan bayangan. Pendekatan yang diusulkan dapat mempelajari variasi background yang dilihat sebagai urutan pixel dalam satu waktu. SOM diterapkan untuk mengetahui similarity nilai pixel dari frame masukan dengan model background. Nilai pixel yang masuk kategori $B M U$ akan ditetapakan sebagai Background dan sebaliknya. Pixel model background yang masuk $B M U$ akan diupdate sesuai dengan aturan dari SOM. Model ini diimplementasikan Singh[12] dalam deteksi objek menggunakan kamera stationer.

\subsection{Background Subtraction}

Pendekatan yang umum digunakan identifikasi objek bergerak dari sekuen video dalam adalah teknik Background Subtraction(BS). $B$ Sakan mengidentifikasi objek bergerak dari tiap frame yang berupa nilai pixel yang berbeda pada tiap frame. Ada beberapa tantangan dalam mengembangkan algoritma $B S$. Pertama algoritma harus tahan tehadap perubahan pencahayaan. Kedua, algoritma dapat menghindari deteksi objek non-stationer pada background seperti: daun bergerak, hujan, salju dan bayangan dari objek [24].

$$
F(x, y)=\left|I_{t}(x, y)-B_{t}(x, y)\right|>T
$$

Formula diatas merupakan notasi untuk mendeteksi objek pada background subtraction dimana $I_{t}$ adalah frame masukan, $B_{t}$ adalah model background, dan $\mathrm{F}$ adalah foreground atau objek bergerak yang terdeteksi. Selisih nilai pixel dari frame masukan dan model background akan dibandingkan dengan nilai threshold. Nilai pixel yang lebih dari nilai threshold akan dideteksi sebagai foreground dan sebaliknya dideteksi sebagai background.

\subsection{Self Organizing Maps}

Self Organizing Maps(SOM) adalah salah satu Algoritma dari Artificial Neural
Network $(A N N)$ yang diperkenalkan oleh Professor Teuvo Kohonen dari Finlandia.SOM termasuk dalam pola pembelajaran tanpa bimbingan (unsupervised learning). Tujuan dari SOM adalah untuk mengkonversi data masukan masukan yang kompleks dan berdimensi tinggi menjadi data yang berdimensi rendah[17]. Hal ini menjadi dasar dari banyaknya SOM yang diaplikasikan dalam proses clustering, pengurangan dimensi data, Data Mining, ekstraksi fitur, dan kompresi data. SOMtermasuk dalam competitive learning dimana setiap neuron(node) keluaran saling berkompetisi untuk menjadi pemenang dan diaktivasi. Hanya ada satu node yang menjadi pemenang dan diaktivasi, hal ini biasa disebut dengan istilah Winner Takes All(WTA).

SOM bekerja feedforward dan completely connected. Feedforwardberarti jaringan hanya berjalan dari masukan ke keluaran tanpa adanya perulangan. Completely connectedberarti setiap node pada lapisan input terhubung kesetiap node pada lapisan berikutnya(output). Koneksi antara node masukan dan keluaran mempunyai bobot. Nilai bobot diinisialisasi dengan nilai acak yang kecil. Perubahan dan penyesuain bobot merupakan kunci utama dalam pelatihan SOM. Layer keluaran biasa berbentuk dalam 1D atau 2D dan biasa berbentuk persegi.

Ada tiga karakteristik dari SOM yang yang disebutkan dalam [13]:

- Kompetisi, Seperti disebutkan sebelumnya, node keluaran bersaing satu sama lain untuk menghasilkan nilai terbaik, paling sering diukur dengan jarak Euclidean (d).Node keluaran yang memiliki jarak Euclidean (d) terkecil antara input dan bobot akan dinyatakan sebagai pemenang.

$$
d(w, x)=\|w-x\|^{2}=\sqrt{\sum_{i=1}^{n}\left(w_{i}-x_{i}\right)^{2}}
$$

- Kerjasama. Node pemenang menjadi pusat peng-updetan bobot pada node disekitar node pemenang. Hai ini mengemulasi perilaku neuron manusia, yang sensitif terhadap output dari neuron lain di lingkungan terdekat mereka. Dalam SOM, semua node tetangga dari node pemenang akan ikut dalam proses update bobot. Dengan demikian, meskipun node pada lapisan output tidak terhubung secara langsung, node tersebut cenderung untuk berbagi fitur-fitur, karena parameter bertetangga (r).

- Adaptasi. Node disekitar node pemenang berpartisipasi dalam adaptasi, yaitu belajar. Dengan kata lain, node ini akan memiliki 
peluang peningkatan memenangkan kompetisi sekali lagi, untuk satu set yang sama.

$$
w_{i j \text { new }}=w_{i j \text { current }}+\eta\left(x_{n i}-w_{i j \text { current }}\right)
$$

$w_{i j \text { new }}$ adalah bobot baru hasil adapatasi (update), $w_{i j \text { current }}$ adalah bobot sekarang, $x_{n i}$ adalah nilai masukan, sedangkan $\eta$ adalah parameter yang biasa disebut dengan laju pembelajaran.

\section{METODE}

Penelitian adalah mencari melalui proses yang bermetode untuk menambahkan pengetahuan itu sendiri dan dengan yang lainnya, oleh penemuan fakta dan wawasan tidak biasa. Penelitian dalam akademik mengacu pada aktivitas yang rajin dan penyelidikan sistematis atau investigasi di suatu daerah, dengan tujuan menemukan atau merevisi fakta, teori, aplikasi dan tujuannya adalah untuk menemukan dan menyebarkan pengetahuan baru. Menurut Dawson [18] ada empat metode penelitian yang umum digunakan yaitu: Riset Aksi, Experimen, Studi kasus, dan Survey. Pada Penelitian kali ini menggunakan metode penelitian eksperimen. Penelitian eksperimen melibatkan penyelidikan perlakuan pada atribut parameter atau variabel tergantung dari penelitinya dan menggunakan tes yang dikendalikan oleh si peneliti itu sendiri.

\subsection{Pengumpulan Data}

Pada penelitian ini menggunakan 2 data sekunder. Kedua data berupa video yang diekstrak menjadi citra. Data pertama berupa video objek orang berjalan pada suatu ruangan yang berdurasi 1 menit 44 detik dengan dimensi frame 352X240, frame rate 29/detik dan format MPG. Data ini diambil pada tanggal 18 Februari 2012 di lobby Gedung Pascasarjana Universitas Dian Nuswantoro Semarang. Data ini diambil dari[10] pada penelitian backgroundSubtraction(BS) mengunakan Fuzzy C-Means dalam menentukan nilai threshold adaptif. Data kedua adalah objek orang berjalan diluar ruangan. Data video dengan dimensi frame video $1920 X 1080$, frame rate 25/detik dan format AVI.

Konversi video menjadi citra menggunakan program konversi yang dibuat dari program matlab. Data pertama (video objek didalam ruangan) diekstrak menjadi 3122 buah citra disimpan dengan format JPG. Hal yang sama dilakukan pada data kedua yang diekstrak menjadi 245 buah citra, disimpan dalam format JPG. Dari hasil ekstraksi data sekunder akan diambil 60 citra berurutan yang akan digunakan sebagai sampel pada eksperimen yang akan dilakukan.

\subsection{Metode yang Diusulkan}

Metode yang diusulkan untuk penelitian ini menerapkan SOM pada background subtraction untuk mengelompokkan pixel pada citra termasuk sebagai background atau foreground. Ditambahkan operasi morfologi dan median filtering dalam rangka meningkatkan performance dari model yang diajukan.

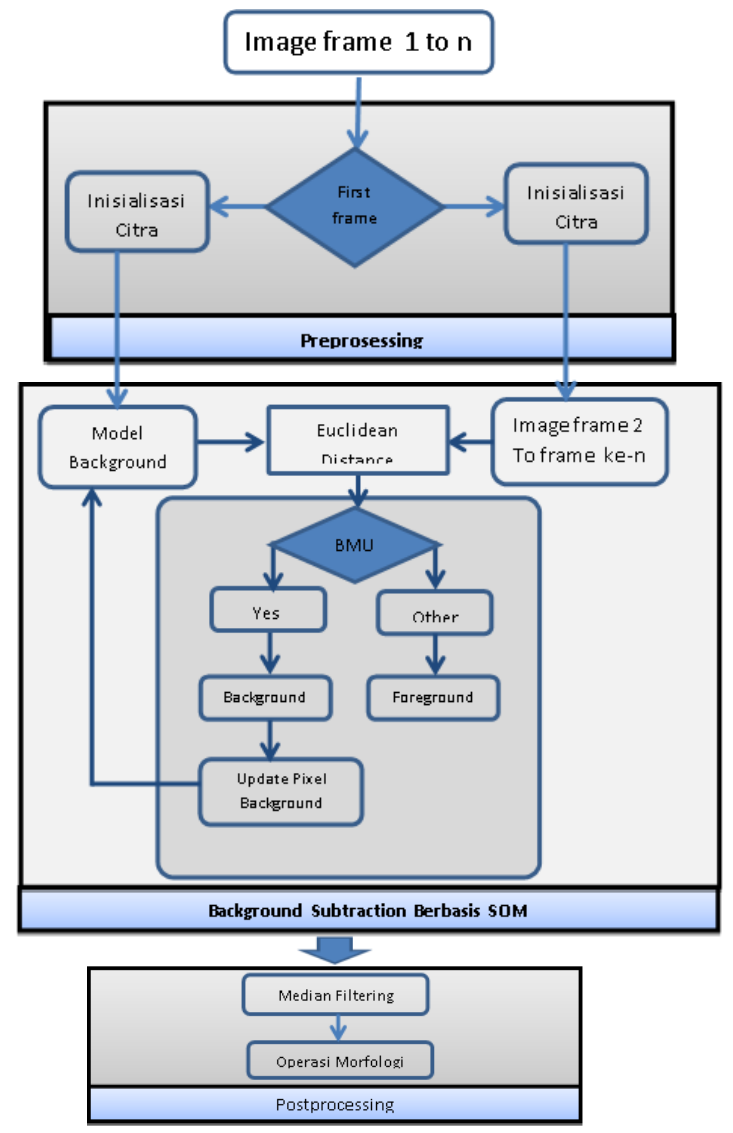

Gambar 1 Hasil dari Pra-Proses (a), Binerisasi (B), dan Segmentasi (c).

Berdasarkan Gambar 1 maka metode yang diusulkan pada penelitian ini dapat dijelaskan antara lain:

\section{- Frame Gambar Masukan}

Data image/citra yang telah disiapkan dalam pengolahan data awal. Di-load oleh model. Data yang digunakan adalah data pada folder eksperimen.

\section{- Pra-proses}




\section{SYSTEMIC}

Vol. 1, No. 1, Agustus 2015, 42-51

Image frame hasil ekstraksi mempunyai ruang warna RGB. Setiap image frame akan masuk proses inisialisai. Pada proses inisialisasi image frame masukan diekstrak menjadi 3 bagian image R,image G, dan image B. Sebelum proses inisilaisasi dilakukan, ditentukan dahulu image yang menjadi model background. Image frame pertama akan digunakan sebagai model background awal. Tahap pra-proses ini dilakukan sebagai persiapan dalam pendeteksian foreground menggunakan $B S$.

- BackgroundSubtraction(BS)

Pada tahap $B S$ berisi beberapa proses.

Dimulai dengan pencarian BestMatchingUnit(BMU) dari model background dengan frame masukan. Proses ini dimulai dengan menghitung jarak kedua citra. Digunakan fungsi jarak.m yang kami buat berdasarkan rumus perhitungan jarak EuclideanDistance.

$$
d(a, b)=\left[\left(a_{R}-b_{R}\right)^{2}+\left(a_{G}-b_{G}\right)^{2}+\left(a_{B}-b_{B}\right)^{2}\right]^{1 / 2}
$$

nilai pixel pada citra hasil pengurangan akan dibandingkan dengan nilai threshold(t) yang telah ditetapkan. Pixel akan masuk kategori $B M U$ jika nilainya lebih kecil atau sama dengan nilai threshold[15]. Pixel yang masuk kategori BMUakan ditetapkan sebagai Background dan diberi nilai 0 , sedang kondisi lainya akan masuk sebagai foreground diberi nilai 1 .

$$
B M U=d(a, b)<t
$$

Sesuai dengan aturan dalam Algoritma SOM, hanya pixel bobot pemenang yang akan diupdate. Formula pengupdetan bobot dibuat berdasarkan[15] yang dituliskan dalam formula dibawah.

$$
B_{t}(i, j)=\left(1-\alpha_{i, j}(t)\right) B_{t-1}(i, j)+\alpha_{i, j}(t) p_{t}(x, y)
$$

Nilai pixel background baru Bt $(i, j)$ diperoleh dari nilai pixel background sebelumnya $\mathrm{B}(\mathrm{t}-1)(\mathrm{i}, \mathrm{j})$ ditambahkan dengan nilai pixel frame masukan yang dikalikan dengan nilai pembelajaran $\alpha(i, j)$. Untuk pengupdetan model background dibangun fungsi modelling.m. Fungsi ini akan mengupdate nilai setiap pixel dari model background, baik itu nilai pixel dari warna merah, hijau, dan biru. Hal ini dilakukan karena model background yang diupdate mempunyai 3 lapisan warna yang biasa disebut dengan ruang warna RGB.

- Pemrosesan Akhir

Tahapan ini diaplikasikan teknik morfologi dan filtering untuk memperbaiki hasil segmentasi dari $B S$. Brutzer[4] mengungkapkan bahwa akurasi hasil dari (BS)dapat ditingkat dengan menambahkan tahapan post-prcsessing setelah tahap BS. Teknik yang dapat digunakan dalam proses akhir seperti operasi morfologi (Closing, Opening ,Dilation, Erotion), Median filter, Wiener filter atau teknik peningkatan citra lain. Dalam penelitian ini diaplikasikan teknik Closing, Opening, Dilation dan Median filter.

- Deteksi Objek dan Penandaan

Tahap terakhir adalah deteksi objek dan penandaan objek(foreground). diaplikasikan algoritma connectedcomponent yang dilanjutkan dengan teknik BoundingBox yang akan memberi batas persegi objek yang terdeteksi pada citra.

\section{SUBJEK EVALUASI}

\subsection{Pengujian Model}

Pada tahapan ini menjelaskan tentang teknik pengujian yang digunakan. Deteksi objek akan dilakukan menggunakan dua metode yaitu background subtractionwith Alpha(BS-alpha)dan background Subtraction berbasis Self Organizing Map(BS-SOM). Akan ditambahkan tahapan pemrosesan akhir setelah proses pengurangan background dari dua metode tersebut. Proses eksperimen dan pengujian menggunakan dua dataset yang telah disiapkan. Tahap ini akan dijalankan deteksi objek menggunakan $B S$ alphadan BS-SOM. Setiap dataset berisi 60 frame. Pengukuran hasil deteksi dilakukan dengan membandingkan citra hasil deteksi yang disegmentasi dan citra groundtruth. Dilakukan pengaturan parameter yaitu: nilai threshold, alfa dan learning rate untuk mendapatkan performa dan akurasi deteksi objek bergerak terbaik

\subsection{Parameter Pengukuran Performa}

Pada tahap ini akan dibahas tentang hasil evaluasi dari eksperimen yang telah dilakukan. Telah disebutkan sebelumnya, evaluasi pada penelitian ini dilakukan dengan mencari nilai Mean Square Error (MSE) dan Peak Signal to Noise Ratio (PSNR). Nilai MSE didapatkan dengan membandingkan citra groundtruth dengan citra hasil deteksi objek bergerak yang disegmentasi dari metode yang diusulkan. Dari ekperimen dengan dataset yang digunakan akan diperoleh nilai MSE dan PSNR dari deteksi objek bergerak menggunakan BS-alpha. Setelah itu dengan dataset yang sama algoritma SOM dan tahap pemrosesan akhir yang diajukan, diaplikasikan dalam proses deteksi objek bergerak 
dengan dataset yang sama. Hasil dari kedua ekperimen kemudian dibandingkan untuk mengetahui ada dan tidaknya perubahan yang terjadi. Dalam penelitian ini diharapkan Algoritma $S O M$ dan tahap pemrosesan akhir yang diajukan bekerja dengan baik.

$$
\begin{aligned}
& \operatorname{MSE}(X, Y)=\frac{1}{M N} \sum_{i=1}^{M} \sum_{j=1}^{N}[X(i, j)-Y(i, j)] \\
& \operatorname{PSNR}(X, Y)=10 \cdot \log _{10}\left(\frac{\max ^{2}}{M S E(X, Y)}\right)
\end{aligned}
$$

\section{HASIL EVALUASI}

Untuk mengetahui hasil deteksi objek, dikembangkan dua program. Program pertama menerapkan BS-alpha dari[5] dengan median filtering dan operasi morfologi dan program kedua menerapkan teknik yang diajukan yaitu $B S$ SOMdengan median filtering dan operasi morfologi. Kedua program ini dibangun dengan bantuan program matlab 2012a. Objek bergerak yang terdeteksi akan ditandai dengan persegi berwarna merah.

Digunakan MSE dan PSNR untuk mengukur hasil segmentasi dari objek. Nilai $M S E$ yang kecil[19] dan nilai PSNR yang tinggi[20] menunjukkan deteksi objek yang akurat berdasar pada hasil segmentasi objek yang baik. Nilai X adalah citra groundtruth sedang nilai $\mathrm{Y}$ adalah citra hasil segmentasi dari teknik yang diajukan. $M x N$ adalah dimensi citra hasil segmentasi.

Dalam penelitian ini metode yang diusulkan akan diterapkan pada sekuen citra. Sebagai perbandingan teknik BS-alphadijalankan pada sekuen images yang sama. Pada pengujian menggunakan dataset pertama, teknik BS-alpha menghasilkan nilai $M S E$ terendah pada 1754,57 dan nilai PSNR tertinggi pada 15,69. Sedangankan rata-rata nilai $M S E$ adalah 4268,501 dan nilai PSNR 12,02. Pada ujicoba menggunakan teknik yang diajukan $B S-S O M$ nilai $M S E$ terendah pada 315,26 dan nilai PSNR tertinggi pada 23,14. Sedangkan rata-rata nilai $M S E$ adalah 1463,736 dan nilai PSNR 17,04. Pada pengujian menggunakan dataset kedua, teknik teknik $B S$ alpha menghasilkan nilai MSE terendah pada 1500,5 dan nilai $P S N R$ tertinggi pada 16,37 . Sedangankan rata-rata nilai $M S E$ adalah 333,176 dan nilai PSNR 13,104. Pada ujicoba menggunakan teknik yang diajukan (BS-SOM) nilai $M S E$ terendah pada 722,82 dan nilai $P S N R$ tertinggi pada 19,54 . Sedangkan rata-rata nilai MSE adalah 3102,17 dan nilai PSNR 13,81
Perbandingan nilai $M S E$ dan $P S N R$ dari teknik $B S$-alpha dengan $B S$-SOMuntuk dataset pertama

\begin{tabular}{|c|c|c|}
\hline & MSE & PSNR \\
\hline BS-Alpha & 4268,501 & 12,012 \\
\hline BS-SOM & 1463,736 & 17,035 \\
\hline
\end{tabular}

Tabel 2

Perbandingan nilai MSE dan PSNR dari BS-alpha dengan $B S$-SOMuntuk dataset kedua

\begin{tabular}{|c|c|c|}
\hline & MSE & PSNR \\
\hline BS-Alpha & 3333,176 & 13,104 \\
\hline BS-SOM & 3102,17 & 13,816 \\
\hline
\end{tabular}

\section{KESIMPULAN}

BackgroundSubstraction(BS)dapat mendeteksi objek bergerak dari sekuen citra. Permasalahan umum dari background subtraction seperti perubahan pencahayaan, bayangan, dan background bergerak juga dapat diatasi. Penerapan algoritma SOM dan tahap pemrosesan akhir yang diisi dengan median filtering dan operasi morfologi dapat membantu meningkatkan akurasi dari segmentasi objek bergerak. Dalam uji coba yang dilakukan pada dua dataset metode $B S$ $S O M$ menghasilkan akurasi segementasi citra yang lebih baik dengan nilai rata-rata $M S E$ yang lebih rendah dan nilai rata-rata $P S N R$ yang lebih tinggi dibandingkan dengan metode $B S$-alphadari penelitian sebelumnya. Dengan demikian penerapan algoritma SOM dan pemrosesan akhir yang berisi median filtering dan operasi morfologi berpengaruh dalam peningkatan akurasi deteksi objek yang dalam penelitian ini diukur dengan kualitas segmentasi citra yang dihasilkan.

Metode BS-SOM dengan median filtering dan morfologi berjalan baik dalam mendeteksi objek bergerak dari dataset yang mengandung permasalahan umum dari teknik $(B S)$ seperti perubahan pencahayaan, bayangan dan objek bergerak. Namun diperlukan pengaturan parameter (threshold dan learningrate) yang tepat dalam menghasilkan deteksi yang akurat. Dalam penelitian selanjutnya dapat ditambahkan metode threshold adaptif dari SOM sendiri atau metode clustering lainya.

Tabel 1 


\section{DAFTAR PUSTAKA}

[1] A. Yilmaz, O. Javed, and M. Shah, "Object tracking," ACM Computing Surveys, vol. 38, no. 4, p. 13-es, Dec. 2006.

[2] K. Toyama, J. Krumm, B. Brumitt, and B. Meyers, "Wallflower : Principles and Practice of Background Maintenance," International Conference on Computer Vision, no. September, 1999.

[3] S. Brutzer, B. Hoferlin, and G. Heidemann, "Evaluation of background subtraction techniques for video surveillance," in CVPR 2011, 2011, pp. 1937-1944.

[4] T. Bouwmans, F. El Baf, and B. Vachon, "Background Modeling using Mixture of Gaussians for Foreground Detection - A Survey," Recent Patents on Computer Sciencee, vol. 1, no. 3, pp. 219-237, Nov. 2008 .

[5] K. Joshi and D. Thakore, "A Survey on Moving Object Detection and Tracking in Video Surveillance System," International Journal of Soft Computing, no. 3, pp. 44-48, 2012.

[6] A. Elgammal, R. Duraiswami, D. Harwood, and L. S. Davis, "Background and Foreground Modeling Using Nonparametric Kernel Density Estimation for Visual Surveillance," vol. 90, no. 7, 2002.

[7] L. Li, W. Huang, I. Y. H. Gu, and Q. Tian, "Foreground object detection from videos containing complex background," in Proceedings of the eleventh ACM international conference on Multimedia MULTIMEDIA '03, 2003, p. 2.

[8] Z. Zivkovic and F. van der Heijden, "Efficient adaptive density estimation per image pixel for the task of background subtraction," Pattern Recognition Letters, vol. 27, no. 7, pp. 773-780, May 2006.

[9] T. H. Chalidabhongse, D. Harwood, and L. Davis, "Background modeling and subtraction by codebook construction," in
2004 International Conference on Image Processing, 2004. ICIP '04., 2004, vol. 5, pp. 3061-3064.

[10] M. A. Soeleman, M. Hariadi, and M. H. Purnomo, "Adaptive threshold for background subtraction in moving object detection using Fuzzy C-Means clustering," in TENCON 2012 IEEE Region 10 Conference, 2012, pp. 1-5.

[11] L. Maddalena and A. Petrosino, "A selforganizing approach to background subtraction for visual surveillance applications.," IEEE transactions on image processing : a publication of the IEEE Signal Processing Society, vol. 17, no. 7, pp. 1168-77, Jul. 2008.

[12] Y. Singh, P. Gupta, and V. S. Yadav, "Implementation of a Self-Organizing Approach to Background Subtraction for Visual Surveillance Applications," International Journal of Computer Science and Network Security, vol. 10, no. 3, pp. 136-143, 2010.

[13] D. T. LAROSE, DISCOVERING KNOWLEDGE IN DATA An Introduction to Data Mining. New Jersey: A JOHN WILEY \& SONS, INC., PUBLICATION, 2005.

[14] R. Khosrowabadi, H. C. Quek, A. Wahab, and K. K. Ang, "EEG-based Emotion Recognition Using Self-Organizing Map for Boundary Detection," 2010 20th International Conference on Pattern Recognition, pp. 4242-4245, Aug. 2010.

[15] G. Bouvier, N. Evrard-Todeschi, J.-P. Girault, and G. Bertho, "Automatic clustering of docking poses in virtual screening process using self-organizing map.," Bioinformatics (Oxford, England), vol. 26, no. 1, pp. 53-60, Jan. 2010.

[16] M. H. Khosravi and R. Safabakhsh, "Human eye sclera detection and tracking using a modified time-adaptive selforganizing map," Pattern Recognition, vol. 41, no. 8, pp. 2571-2593, Aug. 2008.

[17] S. Haykin, Neural Networks: A Comprehensive Foundation, 1st ed. Upper 
Saddle River, NJ, USA: Prentice Hall PTR, 1994.

[18] C. W. Dawson, Projects in Computing and Information Systems. .

[19] H. Ibrahim, "Adaptive Switching Median Filter Utilizing Quantized Window Size to Remove Impulse Noise from Digital
Images," Asian Transactions on Fundamentals of Electronics,

Communication \& Multimedia, vol. 02, no. 01, pp. 1-6, 2012.

[20] A. A. Patil and J. Singhai, "Image denoising using curvelet transform: an approach for edge preservation," vol. 69, no. JANUARY, pp. 34-38, 2010. 